\title{
The Impact of Fear and Rational Appeal Scam Techniques on Individual Susceptibility
}

\section{Siti Nurdiana Abu Bakar ${ }^{\text {* }}$}

${ }^{1}$ Politeknik Tuanku Syed Sirajuddin, Malaysia.

${ }^{2}$ Universiti Utara Malaysia, Malaysia.

${ }^{*}$ Corresponding author: sitinurdiana@ptss.edu.my ${ }^{1 *}$, haryani@uum.edu.my ${ }^{2}$

*ORCID ID: https://orcid.org/0000-0002-7036-1704 *, https://orcid.org/0000-0001-5971-1307
Nur Haryani Zakaria ${ }^{2}$

Received 28/3/2021, Accepted 11/4/2021, Published 20/6/2021

\begin{abstract}
:
Scams remain among top cybercrime incidents happening around the world. Individuals with high susceptibility to persuasion are considered as risk-takers and prone to be scam victims. Unfortunately, limited number of research is done to investigate the relationship between appeal techniques and individuals' personality thus hindering a proper and effective campaigns that could help to raise awareness against scam. In this study, the impact of fear and rational appeal were examined as well as to identify suitable approach for individuals with high susceptibility to persuasion. To evaluate the approach, pretest and posttest surveys with 3 separate controlled laboratory experiments were conducted. This study found that rational appeal treatment has a significantly stronger impact than the fear appeal. This result is a starting point in suggesting that rational appeal is a promising means in persuading individuals with high susceptibility to persuasion.
\end{abstract}

$\underline{\text { Key words: Scam, Fear appeal, Online fraud, Rational appeal, Susceptibility to persuasion, }}$

\section{Introduction:}

The rise of scams, phishing, telephone spam, and fraud has become a never-ending story among all citizens around the world. Unfortunately, statistics showed that scam activities continue to grow yearly. According to Truecaller; (i.e: a smartphone application that helps block unwanted calls); a $24 \%$ rise in the number of spam calls, and Malaysia ranks 19 in the top 20 countries impacted by spam calls observed in 2019 (1). All scams are a form of fraud and in Malaysia, it is punishable by law under Section 420 of the Penal Code and if convicted, are liable to be sentenced under Section 120B (1) of the same Act that carries a maximum of 10 years' jail term and whipping with fine (2). Statistics from the Malaysia Computer Emergency Response Team (MyCERT) under Cyber Security Malaysia (CSM) revealed that since 2008, cyber scam is the highest number of incidents registered annually compared to other cybercrimes, suggesting that there is still a low level of awareness among internet users in Malaysia (3). Recently, Royal Malaysia Police (PDRM) reported statistics showing a total of 8,489 cyber fraud cases were documented between 2018 and the end of August 2019 with losses of RM410.68 million (4).
Scams are known to be a psychological crime because the consequences of scams include both psychological and financial damage to victims. Victims experience loss of self-esteem for being too "stupid" and "careless" to fall into the scam trap. Many of them seemed deeply impacted by this encounter (5). The numbers keep growing and what seems worrying is the fact that people are still being deceived. Different people react to the same situation differently which indicates that some people have a high susceptibility to persuasion and vice versa. Scammers use different techniques to bind their target victims. Some people do not realize that he or she has been scammed for a very long time. Falling victim to a scam once can increase exposure to other fraudsters where their personal details are sometimes sold to other criminals, opening the door to more scam mail, phone calls or home visits (6).

Despite our society's continuing digitization, victimization of cybercrime is expected to continue to rise in the future. Literature showed that some people are easily persuaded while others are not (7). Different people react to the same situation differently. Individual differences combined with 
the scammers' persuasive power may lead to compliance. Gaining more information about how to manipulate or convince people based on their personalities is therefore of great importance to discourage them from scam-related activities. However little is known about appeal techniques or persuasion messages that could be implemented in the cybercriminal area. Fear appeal strategy is used to convey crucial messages that will inspire people to change their habits or develop risk avoidance attitude and follow recommended action. This form of behavior is characterized as a process of danger control; a cognitive process in which techniques are used to avert a threat (8).

Another type of appeal technique is the rational appeal. It is intended to shift the recipients' attitude toward a message focused on the power of reason, logical thinking, and proven statistics. By providing evidence to support the facts, might trigger rational thinking among individuals and assist them in making a rational decision. Mostly the appeal techniques were used in health, environment and advertisement campaigns. For example, a range of work has been carried out on the use of fear appeal in health campaigns (9-13). Meanwhile, advertising campaigns generally use rational appeal as their medium of persuasion (1418). Nevertheless, there seem to be limited numbers of studies focusing on the relationship between appeal techniques and an individual's personality that could help to raise awareness against scam.

Thus, this study aims to bridge this gap by examining the effect of appeal techniques on an individual's personality and to identify a suitable appeal technique for individuals with high susceptibility to persuasion. To evaluate this approach, two appeal techniques have been implemented (fear and rational appeal) and three separate controlled laboratory experiments were conducted. This study does not focus on any specific scam types instead, scam is assumed as a whole identity.

The remainder of this paper is structured as follows. After research's objectives has been clarified, connection between appeal techniques and scam victims' personality is being discussed. With the use of StP scale and appeal techniques methodology, results show that fear appeal technique is effective on people with high susceptibility to persuasion. Optimistically, findings from this research will provide relevant authorities with guidelines for considering the use of appeal techniques in their anti-scam awareness campaigns and at the same time contribute to the existing knowledge on the relationship between appeal technique and behavior change among individuals.
The last section draws conclusions and directions for future work.

\section{Background and Related Studies: Scam}

According to (19), scam is defined as an illegal money-making plan by tricking people into it. Consumer scams include the manipulation of individuals who knowingly engage in exchange to obtain tangible or intangible goods, services or financial returns that are never supposed to be delivered or misrepresented (20). Scams came in many forms and methods. Usually the words such as "fraud", "lie" and "swindle" are synonymous with a scam. Product scam for example; involving fake goods such as miracle remedies and fake gemstones, as well as dubious lotteries, award draws, sweepstake games, and auction sites. Several websites have organized bogus competitions or sales, asking unsuspecting customers to register with their data to duplicate them. Work from home scams takes the benefit of technology where job seekers around the globe involved in remote job opportunities. These roles are more comfortable and flexible than traditional office positions, favored by employees with growing families, freelancers and many others who benefit from home-based workfriendliness. Instead, job seekers are tasked with facilitating questionable acts that are often illegal like a pyramid scheme, return cash scheme and cashing bad checks. The internet auction scam refers to the wrong portrayal of an advertised item for sale via the internet or the failure to deliver goods purchased via the auction website. It may seem like a minor crime, but it has severe implications.

In a romance scam, the victim is persuaded to make a payment to the person they met and with whom they believe they are in a relationship with (21). Scammers usually search for insecure, emotional and lonely people seeking a partner or relationship. According to Chief Assistant Director of the Cybercrime Investigation Unit Bukit Aman, a total of RM83.6 million lost have been reported in 2018 related to romance scams (22). Meanwhile, in an investment scam, a criminal persuades his target to move his money into a fictitious fund or to pay for a fraudulent investment. These scams include investment in things like gold, real estate and cryptocurrencies (21). For advance fee scam or also known as "419 scams", victims are convinced to advance comparatively small amounts of money in the expectation of obtaining a much greater profit (23). Any misleading or malicious economic activity that induces people to do something that is not in their interests is fraudulent and it includes 
phishing (scamming) too. One may include scams under a wider concept of fraud that extend well beyond consumers. Examples include schemes involving academic dishonesty (e.g. students cheating or falsifying applications, university professors misrepresenting test results), lying on applications for mortgages or jobs, embezzlement, workplace bribery, medical fraud, and tax evasion.

The recorded statistics are alarming in terms of customer losses, but the issue is likely to be even worse. Some scams are unlikely to be recorded because victims are typically embarrassed, resigned or discouraged and others may believe there is no need to file a police report because law enforcement is often unable to investigate internet crimes due to their anonymity and insurance does not cover scam damages without court involvement (24).

\section{Susceptibility to Persuasion}

Scam attacks generally aim to manipulate end-users to comply with the scammer's request and this is known as the art of persuasion. Persuasion, also known as coercion, is a phenomenon in which the convinced subject is affected by the plausibility of the story and when people consider a plot plausible, they are more likely to invest in it (25). Individuals who considered scams plausible were more likely to cooperate with scammers particularly when there were elements of social influence, authority influence, and marketing offer (legal or illegal). Persuasive technology (PT) has been and continues to be used to alter behaviors in various areas of human activities such as health, education, commerce, etc. In PT research, Fogg (26) proposed seven persuasive strategies for changing behaviors: Reduction, Tunneling, Tailoring, Suggestion, SelfMonitoring, Surveillance, and Conditioning. While, Cialdini and Goldstein (27) proposed six persuasive strategies, which are mainly applied in the field of marketing and advertising; Reciprocity, Scarcity, Authority, Commitment and Consistency, Liking and Consensus. Meanwhile, Oinas-Kukkonen and Harjumaa (28) extended the Fogg's seven sets of persuasive strategies to 28 strategies, which are categorized into three broad categories: Primary Task Support, Dialogue Support, and System Credibility Support. Research has however shown that individuals can vary in their sensitivity to different PT strategies. This realization prompted a shift in PT design from the conventional one-sizefits-all approach to a customized approach that adapts to individual preferences (29). In this study, ten susceptibility factors introduced by Modic, Anderson and Palomäki (30) were selected because believe these factors are relevant in scam context and easily acceptable and understood by our respondents, which will promote a consistent interpretation of their responses.

\section{Susceptibility to Persuasion Scale}

Susceptibility to Persuasion (StP) scale is a psychometric tool used to measure factors that contribute to individuals' compliance with fraudulent offers such as scam compliance. A brief and automated interpretation of the results is displayed at the end of the questionnaire which is freely accessible. The results of the test can be used to predict who will be more likely to become a victim of cybercrime. StP tool was extended to StPII which is commonly used for hiring in certain professions, for the screening of military personnel or to establish the psychological characteristics of criminal hackers. An initial version of StP was developed and tested by Modic and Lea (31) on the reactions of fraud victims. It was designed from scratch, however, and did not implement previous scale development factors. Besides, the StP's ecological validity studies have not been established beyond a reasonable doubt. Thus, StP-II is developed in 2018. The scale is constructed from previously established and validated particulate scales in the fields of social psychology and behavioral economics. It contains 54 items, ten subscales, and further six sub-sub-scales. The ten subscales are demographic information, SII (Susceptibility to Interpersonal Influence), NCS (Need for Cognition Scale), PFC-B (Preference for Consistency), AISS (Arnett Inventory of Sensation Seeking), ATA (Attitude Towards Advertising), BSCS (Brief Scale of Self-Control), CFC (Consideration of Future Consequences Scale), CNFU-S (Consumer Need for Uniqueness Scale) and DOSPERT-R (Domain-Specific Risk-Taking Scale). Listed in Table 1 below are previous researches on persuasion factors adapted into the development of StP and StP-II whereby each scale factors have been tested, verified and refined before selection (25). 
Table 1. Existing Research on Persuasion Factors.

\begin{tabular}{|c|c|c|c|}
\hline \multicolumn{2}{|r|}{ Scale Factors } & \multicolumn{2}{|r|}{ StP-II } \\
\hline 1) & Social influence & Cialdini, R.B. (32). & $\begin{array}{l}\text { Susceptibility to Normative Influence (SNI) } \\
\text { (33). }\end{array}$ \\
\hline 2) & $\begin{array}{l}\text { Need for cognition /self- } \\
\text { consciousness }\end{array}$ & N/A & Need for Cognition Scale (NCS-18) (34) \\
\hline 3) & Need for consistency & 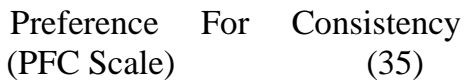 & Preference For Consistency (PFC Scale) (35) \\
\hline 4) & $\begin{array}{l}\text { Attitudes } \\
\text { advertising }\end{array}$ & N/A & Attitude Towards Advertising (ATA) scale (36) \\
\hline 5) & High-risk preference & $(37) \&(38)$ & DOSPERT \\
\hline 6) & Self-contro & (40) & Brief Scale of Self-Control (BSCS) \\
\hline 7) & Liking and similarity & Cialdini, R.B. (32). & N/A \\
\hline 8) & Sensation seeking & N/A & $\begin{array}{l}\text { Arnett Inventory of Sensation Seeking (AISS) } \\
(42)\end{array}$ \\
\hline 9) & $\begin{array}{l}\text { Scarcity/Need } \\
\text { uniqueness }\end{array}$ & Cialdini, R.B. (32). & $\begin{array}{l}\text { Consumer Need for Uniqueness Scale (CNFU- } \\
\text { S) (43) }\end{array}$ \\
\hline & ) Trust and autho & R.B. (32). & N/A \\
\hline & ditate & N/A & CFC Scale (44) \\
\hline & ) Illusions of control & Taylor \& Brown (45) & N/A \\
\hline & ) Need for similarity & N/A & Domain-specific Impulsivity Scale (DSIS) (46) \\
\hline
\end{tabular}

Based on existing studies, the StP-II scale seems promising in evaluating individual differences in susceptibility to persuasion and extends across different contexts such as psychology and human development. Modic, Anderson and Palomäki (25), emphasized that this rubric will not guarantee that you will or will not fall for a scam, but argued that StP-II, regardless of context plays a crucial role in understanding behavior modification strategies. For this research, the StP-II scale is chosen since most of the questions in this survey relate to scam activities and compliance.

\section{Victims' Personality}

There has been some assumption about the scam victims' personality. A study by Whitty (47) formulated several traits for romance scam victims. She discovered that those tricked by romance scams scored high on the impulse subscale of urgency and absence of self-control, tended to be middle-aged people, scored higher on the sensation seeking and they find it hard to get away from the scam (i.e.: addictive disposition), highly educated people and less kind individuals with no friends are among the traits. Whitty (48) further suggested that educated people would be more likely to say that they can detect a scam and believe they're in charge, while others may have little influence over them, unknowingly they are dragged into the scam as consequences. Williams, Beardmore and Joinson (49) found that those who were most inclined to participate in risky purchasing practices are likely to have been the victims of fraud. One who has witnessed a significant negative life incident (divorce, a death in the family, a loss of a job, experiencing a financial crisis) are more likely to become a scam victim (30). Study in 2017 by Van de Weijer and Leukfeldt (50) shows that men were also far more likely than women to become victims of online consumer fraud. With the continuing digitization of our society, the victimization of cybercrime is likely to increase in the future.

\section{Appeal Techniques:}

There are many kinds of appeals used in advertising such as emotional, rational, music, sex, masculine/feminine, brand, scarcity, adventure, romance, and sensitivity appeals. Fear appeal is derived from the emotional appeal group which also consists of social, humor and personal appeal (51). In this present study; fear and rational appeal were chosen. A fear appeal has been proven in many pieces of research to motivate behavior change; from risky behavior to safer alternative behavior $(52,11,53)$. Meanwhile, rational appeal focus on statistics, numbers and facts. Not many researches focus on the use of rational appeal insecure behavior, most of the studies focus on rational appeal as advertising appeal. They can, however, show that rational appeal often motivates respondents to the desired position of the attitude by manipulating the respondents' thoughts $(54,14)$.

\section{Fear Appeal}

Fear appeals messages aim to arouse fear by emphasizing the possible danger and damage that people will face if they do not follow the message's recommendations (55). As stated by the Extended Parallel Process Model (EPPM) by Witte (56), when individuals are exposed to a fear appeals message, two simultaneous message appraisal 
processes occur: threat and efficacy appraisal. The threat appraisal includes determining the magnitude of the danger (i.e. how severe the negative impacts are) and the susceptibility to the danger (i.e. how likely it is to come across such negative effects). The EPPM specifies that fear is aroused when both expectations are strong, thus leads to more action. After experiencing fear, individuals will respond in a manner that is positive or negative, depending on their efficacy appraisal. Umber, Ghouri, Sultan and Yousaf (9) conduct an assessment of behavioral change related to fear appeal messages on the dengue campaign. From their findings, they concluded that fear appeal messages arouse awareness, fear, and anxiety among respondents and lead to a change of behavior into protection motivation mode. Strong efficacy of the fear appeal messages also increases threat appraisal and coping appraisal among individuals $(57,58)$. This research is supported by Samtani, Zhu and Yu (8) where they found that stronger threat severity does not reduce users' self-efficacy but increasing it. Fear appeal messages also had a high impact on society when the threat and recommendation are made in their respective mother tongue (59). Although often effective in controlling an individual's security behavior, worth noting that existing work from various fields, such as marketing, communication, politics, and health also questioned the use of fear appeals as motivational drives (60). As proven by Shin, Ki and Griffin (61), fear appeal elicits negative emotions, so it is important to keep the perceived threat controllable and the use of fear appeal in advertising is complex and requiring vigilant planning. While a significant amount of previous studies focused on fear appeal in the context of information security and health campaign, unfortunately, there were limited resources on the use of fear appeal in scam context specifically.

\section{Rational Appeal}

A rational appeal is a message containing proven facts. The content emphasizes the logic of persuasion and reasoning. In the advertising industry, rational appeal introduces to the consumer the qualities and benefits of the goods. Rational appeals attempt to convince people by making the facts available to them and by giving proof to demonstrate its' effect. According to Meinard and Tsoukiàs (62), people who are strongly inclined towards reasoning and learning make an in-depth evaluation of the depicted knowledge as opposed to those who are not much concerned with detailed analysis. Some information sometimes contains differences in opinions to give its users logic and reasoning. Certain elements that affect the rational appeal and one of them is; the level of an individual's involvement (implication on their life). For example, if scam incidents happen will they lose a lot of money or it is just a scratch on the surface? This situation requires logical thinking. And of course, when it involves bad implication on them, they will choose rationally instead of emotional judgment. Research by Malik and Tanveer (17) showed that in developing rational appeal messages consider educative information to convey logic to the respondents. It is crucial to insert proven facts to create non-disputed messages. Even though not many researchers use rational appeal in the information security area, basic findings on the use of rational appeal as behavior change catalysts from advertising research can be counted in $(63,54,16)$. In this case, a key question is raised:

Do fear and rational appeals have the same impact on individuals with high susceptibility to persuasion?

\section{Methodology:}

In analyzing the impact of fear and rational appeal tactics, a quantitative approach were employed to test the hypotheses. Pretest, posttest surveys and controlled laboratory experiments were conducted. The experiment consisted of three experimental treatments (fear appeal, rational appeal, and control group). Before the survey was conducted, all respondents had been given information regarding this research for them to make an informed consent to participate. To determine which appeal techniques can persuade individuals to stay away from scam activities, within-subjects design is chosen. This design requires fewer participants and reduces the amount of error arising from the natural variance between individuals (64). For this experiment, the dependent variable is the individuals' susceptibility level to persuasion, whereas the appeal techniques are the independent variables. Our hypotheses were as follows:

$H_{0}$ - There are no differences in types of appeals between individuals with high susceptibility to persuasion.

$H_{1}$ - Rational appeal has a stronger impact on individuals with high susceptibility to persuasion than fear appeal.

\section{The Apparatus}

Apparatus consists of an online survey and flyers. In the pretest condition, the survey was adopted from the "Susceptibility to Persuasion-II Scale" developed by Modic, Anderson and 
Palomäki (30). It is in the form of a Likert scale of 7 points, with choices ranging from strongly disagree to strongly agree. This survey is used to determine an individual's susceptibility to persuasion toward scam activities based on 10 persuasion factors; need for cognition, need for consistency, need for similarity, attitudes towards advertising, high-risk preferences, social influence, self-control, sensation seeking, ability to premeditate and uniqueness. The survey was done in dual-language (English and Bahasa Malaysia). The main reason for the duallanguage is because of the respondents' background. For non-IT people, some words might not convey its true meaning as intended. To assess pretest and posttest conditions, the same survey is used throughout this experiment. A one-page flyer with two different infographic designs was used in this experiment as part of the treatment media. They had the same structures: a headline, images related to the issue and messages with information under the image. Flyer A (fear appeal): focus on the effects and harms that scam can inflict on themselves and their loved ones to arouse fearful feeling meanwhile flyer B (rational appeal): contain statistical data and proven research facts about scam to ignite rational and logical thinking among respondents as illustrated in Figure 1. The contents of the flyers were developed by the researchers and were sent for expert reviews. There were five expert reviewers involved in the assessment of the flyers. These wellknown reviewers were identified based on their diversity of expertise in the fields of psychology related to crime based and computer security area. All experts were contacted by email to give their opinions and comments on the flyer's messages and after that appropriate improvement was done to create better content.

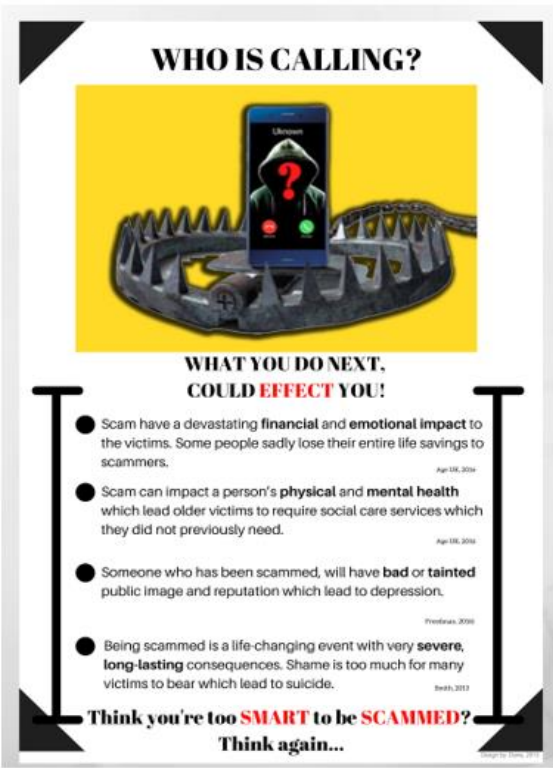

(A)

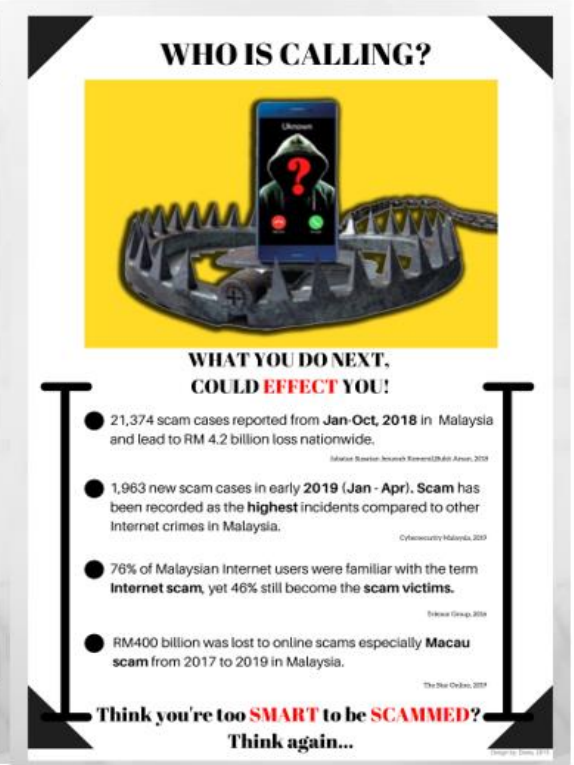

(B)

Figure 1. Examples of the Flyers: (A) Fear Appeal and (B) Rational Appeal.

\section{Measurement}

Susceptibility to persuasion level for each individual was obtained directly from the adopted survey as mentioned before. The survey consists of ten subscales; need for cognition, need for consistency, need for similarity, attitudes towards advertising, high-risk preferences, social influence, self-control, sensation seeking, ability to premeditate and uniqueness. 54 statements were included that are answered on a 7-point Likert scale ranging from 'strongly agree' to 'strongly disagree'. The survey includes statements such as "advertising results in better products for the public" and "if it were possible to visit another planet or the moon for free, I would be among the first to sign up". The second part of the test presents a range of possible scams (such as a romance scam or auction scam) and asks the user to respond whether they find the scams plausible or not. Participants are given a score out of 7 in each of the 10 areas. In result analysis, Analysis Of Variance (ANOVA) one-way test is used to determine whether there are any statistically significant differences between the means of the three independent groups. Additionally, to determine which pairs of means are statistically different, Tukey's post hoc test is implemented.

\section{Procedures}

At the beginning of Phase 1: in the pretest phase, respondents were asked to answer an StP-II survey which have been converted into a duallanguage survey by the researcher for ease of understanding among respondents and to aid in data 
collection stage. It is estimated that the respondents took about 15 minutes to finish the process. Informed consent and demographic information were obtained from each respondent. They were asked to include their age, gender, education background, and internet literacy information.

During the experiment (2nd Phase): The experiment was conducted in a controlled laboratory environment to avoid any distractions. Respondents were given a brief introduction to scam, scam activities, how to identify a scammer and an explanation on an individual's differences regarding persuasion. Respondents were given extra information about the assigned appeal techniques. This was done under the assumption that the respondents should be aware of the appeal technique being employed and equipped themselves with some knowledge. After the briefing process, fear appeal flyers were distributed among themselves. Respondents were given 10 minutes to fully understand and review all the information thoroughly in that one-page flyer. Participants were highly encouraged to ask the experimenter questions concerning details about the flyers. Respondents were not allowed to have any discussion with each other. After 10 minutes, all respondents remain seated and were asked to answer a posttest StP-II survey again. The same survey in pretest and posttest were used to assess any impact these treatments posed on our respondents. This entire experiment takes about 40 minutes to be completed.

At the end of the experiment: Before leaving the room, each respondent handed over the flyers to the experimenter. These procedures were repeated for rational appeal treatment with a time gap of 6 weeks. According to Brown, Irving and Keegan (65), the time gap between a pretest and a posttest is somewhere between 3 to 6 weeks where the respondents might already forget their answers for the first time. In Figure 2, a summary of this experiment is presented in the form of a flow diagram.

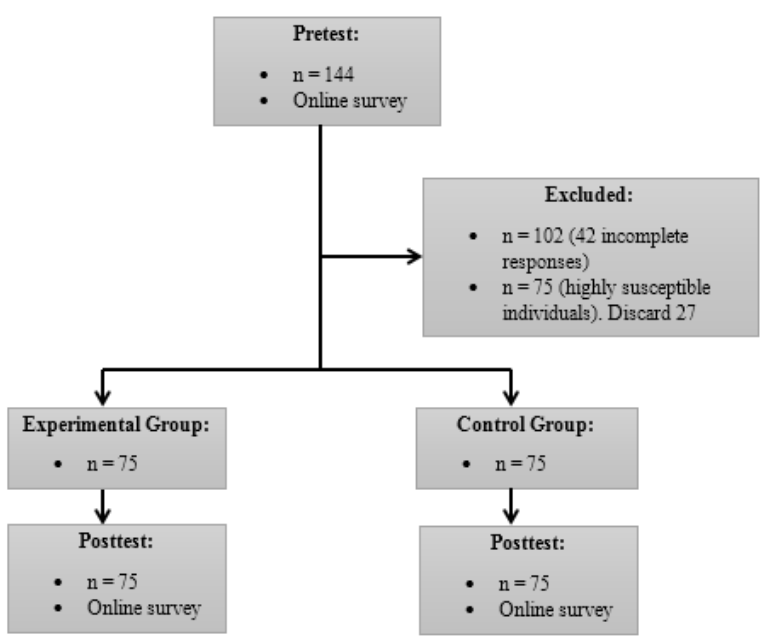

Figure 2. Experiment Flow Diagram.

\section{Results and Findings:}

A total of 144 students took part in the experiment. Data were screened for empty responses, leaving us with 102 students who completed their given tasks. The response rate was $70.8 \%$. From this, only 75 respondents' show high susceptibility to persuasion, $33(44 \%)$ male and 42 (56\%) female were chosen as seen in Figure 3. This research focus primarily on individuals with high susceptibility to persuasion since this focus group is the one with high-risk attitudes towards scam compliance.

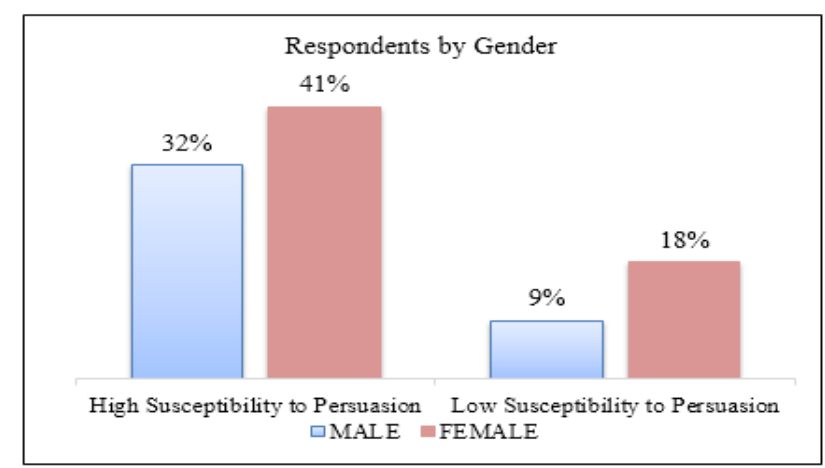

Figure 3. Respondents by Gender

The mean age for the participants was approximately 20 years with a standard deviation of 2.3. All of the respondents (100\%) completed their SPM level and currently pursuing a study in higher education. More than half $(n=50,67 \%)$ of the respondents had experiences using the internet where they describe as "I know what IT means and have an account on eBay, Facebook, Amazon, etc.". As seen in Figures 4 and 5, the highest internet literacy level comes from respondents with 22-25 years of age with the lowest one from the 18-21 age group with 3\%. Meanwhile, the Diploma level (age group 21-26) has the highest 
internet literacy among other levels of the education group.

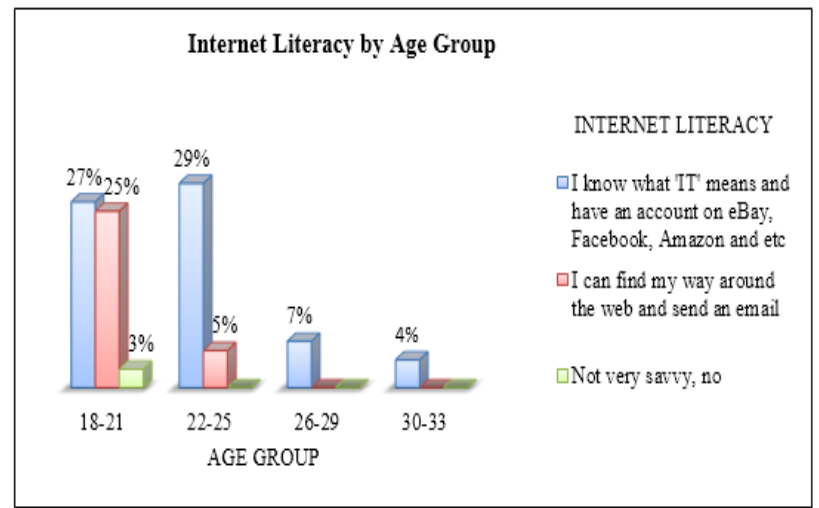

Figure 4. Internet Literacy by Age Group

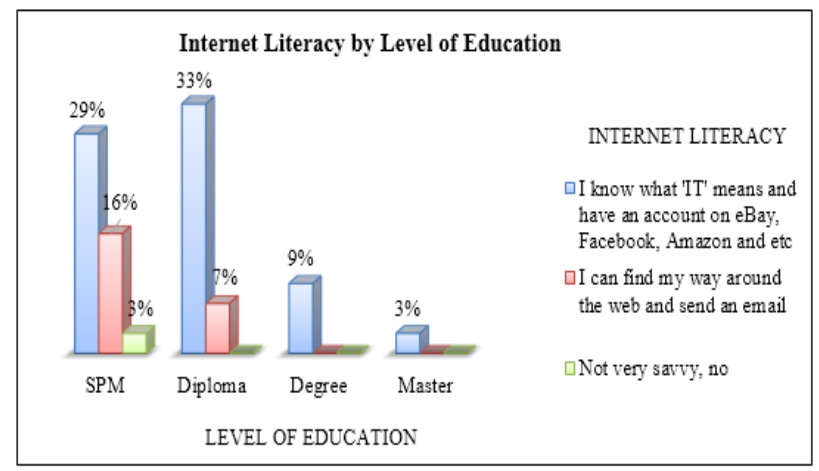

Figure 5. Internet Literacy by Level of Education

Since this persuasion scale is an established measurement adopted directly from Modic, Anderson, and Palomaki (25), the answer is used as it is to determine whether those respondents have high susceptibility or low susceptibility to persuasion. The reason behind this selection is because researcher assumed individuals with low susceptibility to persuasion do not pose a high-risk attitude thus they were excluded from this experiment. The results for the independent variables are provided in Table 2 . From the mean differences P1-P2, a rational appeal has the highest value compared to fear appeal and no appeal treatment. To prove this result, ANOVA test compared the 3 treatments.

Table 2. Mean Differences for Pre and Post Test.

\begin{tabular}{lllllll}
\hline $\begin{array}{l}\text { Pretest } \\
\left(\boldsymbol{P}_{1}\right)\end{array}$ & \multicolumn{2}{l}{ Posttest $\left(\boldsymbol{P}_{2}\right)$} & & \multicolumn{2}{c}{ Differences $\left(\boldsymbol{P}_{\boldsymbol{1}}-\boldsymbol{P}_{2}\right)$} \\
\hline \multirow{3}{*}{4.06} & $\boldsymbol{F A}$ & $\boldsymbol{R A}$ & $\boldsymbol{N A}$ & $\boldsymbol{F A}$ & $\boldsymbol{R A}$ & $\boldsymbol{N A}$ \\
& 3.61 & 3.30 & 4.01 & 0.46 & 0.76 & 0.04
\end{tabular}

Note: $F A=$ Fear Appeal, RA=Rational Appeal, NA=No Appeal
A one-way ANOVA compares the impact of appeal techniques on individuals' susceptibility levels in fear appeal, rational appeal, and no appeal conditions. Table 3 shows that appeal techniques have had a significant effect on respondents with high susceptibility to persuasion, the $p<.05$ level for the three conditions $[\mathrm{F}(2,222)=11.88, \mathrm{p}=$ 0.000]. To specify which appeal techniques has the most impact on individuals, Tukey's test is used.

Table 3. Significant Differences between Appeal Techniques.

\begin{tabular}{llllll}
\hline & $\begin{array}{l}\text { Sum of } \\
\text { Squares }\end{array}$ & df & $\begin{array}{l}\text { Mean } \\
\text { Square }\end{array}$ & F & Sig. \\
\hline $\begin{array}{l}\text { Between } \\
\begin{array}{l}\text { Groups } \\
\text { Within }\end{array}\end{array}$ & 19.476 & 2 & 9.738 & 11.880 & .000 \\
$\begin{array}{l}\text { Groups } \\
\text { Total }\end{array}$ & 181.975 & 222 & .820 & & \\
& 201.451 & 224 & & &
\end{tabular}

Post hoc comparisons using the Tukey's test indicate that the mean score for the rational appeal condition $(\mathrm{M}=0.76, \mathrm{SD}=0.75)$ was significantly different than the no appeal condition $(\mathrm{M}=$ $0.04, \mathrm{SD}=1.05)$. However, the fear appeal condition $(\mathrm{M}=0.46, \mathrm{SD}=0.88)$ has a modest interaction effect between rational and no appeal conditions as in Table 4.

Table 4. Mean and Standard Deviation between Appeal Techniques.

\begin{tabular}{lllll}
\hline & $N$ & Mean & Std.Deviation & Std.Error \\
\hline $\begin{array}{l}\text { Fear } \\
\text { Appeal }\end{array}$ & 75 & .4577 & .88395 & .10207 \\
$\begin{array}{l}\text { Rational } \\
\text { Appeal }\end{array}$ & 75 & .7617 & .75232 & .08687 \\
$\begin{array}{l}\text { No } \\
\text { Appeal } \\
\text { control }\end{array}$ & 75 & .0439 & 1.05441 & .12175 \\
$\begin{array}{l}\text { group) } \\
\text { Total }\end{array}$ & 225 & .4211 & .94833 & \\
\hline & & & & .06322
\end{tabular}

Taken together, these results suggest that rational appeal indeed showed to affectindividuals with high susceptibility to persuasion. Specifically, our results suggest that rational appeal has a significantly higher persuasive influence on individuals compare to fear appeal. However, it should be noted that both appeal techniques do have a significant impact on individuals. For the control group, it does not appear to have significant results on an individual's susceptibility level. 

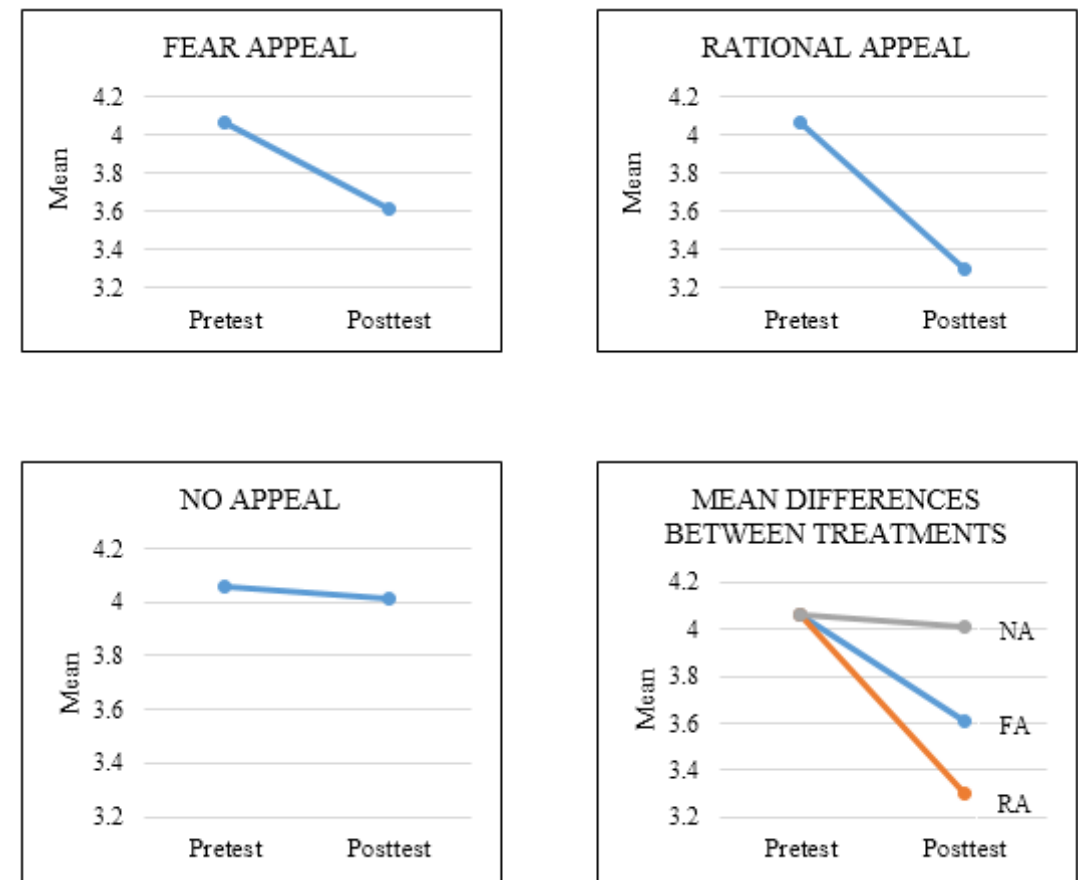

Figure 6. Appeal Techniques Effect for Pre and Posttest

Figure 6 shows the interaction effects of appeal techniques for pre and post conditions. When respondents are exposed to rational appeal treatment, it generates the highest means. This proves that rational appeal has a great effect on individuals with high susceptibility to persuasion. Our hypotheses testing were summarized in Table 5 below. The null hypothesis is rejected. H1 hypothesis were strongly supported $(\mathrm{M}=0.76, \mathrm{p}$ $<.05)$.

Table 5. Summary of Hypotheses Testing.

\begin{tabular}{lll}
\hline Hypotheses & Supported? \\
\hline$H_{0}-$ There are no differences in types of & No \\
appeals between individuals with high & \\
susceptibility to persuasion. & & \\
$H_{1}-$ Rational appeal has a stronger Yes \\
impact on individuals with high \\
susceptibility to persuasion than fear \\
appeal.
\end{tabular}

\section{Discussion:}

This section will entail further some discussion based on from the results and findings shared in previous section. From this study, fear appeals do not have a significant impact on individuals with high susceptibility to persuasion. As we all know, this type of respondent does like to take the risk and act recklessly however, to suppress this behavior by putting fear into them is not a good tactic. There are several reasons for this; as we all know, the fear appeal has been used widely in health campaign and many kinds of research have been done on it to promote its effectiveness. In the scam context, putting fear into individuals might not work well because respondents feel that they are in control of their actions and decisions. They feel confident that they can recognize and avoid scam like activities, unfortunately, most of the time, they don't. When overconfident kicks in, that is when they realized they have fallen victims to scammers. Unlike health, they cannot control how their body works, for example, their metabolism rate, getting cancer at a young age or having allergies to drugs or food. So in return, they have feelings of fear and worries inside them when talking about health. They tend to follow recommended actions such as quit smoking, take a balanced diet or do health checkups once a year. Unlike scam, even when their loved ones advise them to stay away from scam like activities, they still feel that they are in control of their actions and they know what they are doing. So for scam campaign advertisers, fear messages might not induce much fear in people to keep them from being scam victims.

This result act as starting point in identifying rational appeal as a persuasive technique that can be implemented in the anti-scam awareness campaign. Rational appeal deals with statistics and proven facts. Rational appeals stimulate people to employ logical reasoning, to get them to act correctly, while fear appeals depend on feelings. People tend to believe evidence and information when it comes to risky behavior such as a scam. Even with individuals who have a high susceptibility to persuasion, when it comes to money or to protect their loved ones from danger, 
they will think rationally and logically in making wise decisions. Rational appeal knock someone a sense of reason. To make a better judgment, they need a good reason. Hopefully, this research contributes considerably to the established literature in cybersecurity. Appeal techniques' effect, particularly in scam context, was not researched before. Therefore, this study fills the research gap and adds to the current body of knowledge.

\section{Conclusion:}

This study is intended to examine the impact of appeal techniques on an individual's personality and to discover an appeal technique for individuals with high susceptibility to persuasion. From findings, rational appeal techniques best suit individual's with high susceptibility to persuasion rather than fear appeal technique. Rational appeals that convey logic and educative information with proven facts prove to be effective in persuading people to be vigilant when confronting lucrative offers and cunning scammers. The limitation of this study is that the subject pool includes higher education students only. This demographic could be expected to have little knowledge and experience in dealing with scam activities and only focus on certain types of scam related to them such as accommodation scams and counterfeit goods.

Future research would fairly reflect data from all age groups to broaden the diversity of data collection. It is also interesting to see how the appeal techniques can be combined to provide better appeal messages and at the same time able to persuade people to be wary of scammers. Another worthwhile direction is to investigate other appeal techniques that can be used to develop effective campaigns' content to facilitate enforcement agencies in combatting scams.

\section{Acknowledgement:}

This research was supported by Ministry of Higher Education (MoHE) through Fundamental Research Grant Scheme (Ref: FRGS/1/2020/ICT03/UUM/02/1(S/O

Code:14839)). The authors also would like to thank all the participants and polytechnic administrators which involved in this study especially from Politeknik Tuanku Syed Sirajuddin (PTSS). The content of this article is solely the responsibility of the authors and does not necessarily represent the official views of the MoHE, Malaysia.

\section{Authors' declaration:}

- Conflicts of Interest: None.
- We hereby confirm that all the Figures and Tables in the manuscript are ours. Besides, the Figures and images, which are not ours, have been given the permission for re-publication attached with the manuscript.

- Ethical Clearance: The project was approved by the local ethical committee in our organization.

\section{References:}

1. Wong A. Malaysians on receiving end of world's biggest percentage of scam calls, new data claims: Malaymail. 2020. Retrieved from: https://www.malaymail.com/news/malaysia/2019/1 2/04/malaysia-has-worlds-biggest-percentage-ofscam-calls-new-data-claims/1815984

2. International Comparative Legal Guides. Cybersecurity Laws and Regulations 2020. United Kingdom:Global Legal Group. 2019. Retrieved from: https://iclg.com/practice-areas/cybersecuritylaws-and-regulations

3. New Straits Times. Cyber scams top the list every year. 2020. Retrieved from: https://www.nst.com.my /news/nation/2019/ 08/ 512452/cyber-scams-top-list-every-year

4. The Malaysian Reserve. Scammers looted RM410m up till August since last year. 2020. Retrieved from: https://themalaysianreserve.com/2019/10/30/scamm ers-looted-rm410m-up-till-august-since-last-year/

5. Norris G, Brookes A, Dowell D. The Psychology of Internet Fraud Victimisation: A Systematic Review. Journal of Police and Criminal Psychology. 2019;34(3),231-245.

6. National Trading Standards (NTS). National Trading Standards - Scams Team Review. United Kingdom: RAND Corporation. 2016. Retrieved from:

http://https://www.rand.org/pubs/research_reports/R R1510.html

7. Henderson R. The Science Behind Why People Follow the Crowd. Why do other people influence us so much? 2017. Retrieved March 10, 2020, from: https://www.psychologytoday.com/us/blog/afterservice/ 201705/ the-science-behind-why-peoplefollow-the-crowd

8. Samtani S, Zhu H, Yu S. Fear Appeals and Information Security Behaviors: An Empirical Study on Mechanical Turk. AIS Transactions on Replication Research. 2019;5,1-22.

9. Umber S, Ghouri M, Sultan K, Yousaf M. Dengue Campaign and the Youth Behavior: A Study of Fear Appeal Impacts. Global Media Journal: Pakistan Edition. 2016;9(1).

10. Daudé É, Mazumdar S, Solanki V. Widespread fear of dengue transmission but poor practices of dengue prevention: A study in the slums of Delhi, India. PLOS ONE. 2017;12(2),0171543.

11. Boshoff C, Toerien L. Subconscious responses to fear-appeal health warnings: An exploratory study of cigarette packaging. South African Journal of Economic and Management Sciences. 2017;20(1). 
12. Simpson J. Appeal to fear in health care: appropriate or inappropriate? Chiropractic \& Manual Therapies. 2017;25(1).

13. Carey R, Sarma K. Threat appeals in health communication: messages that elicit fear and enhance perceived efficacy positively impact on young male drivers. BMC Public Health. 2016;16(1).

14. Grigaliunaite V, Pileliene L. Emotional or Rational? The Determination of the Influence of Advertising Appeal on Advertising Effectiveness. Scientific Annals of Economics and Business. 2016;63(3),391-414.

15. Sudbury-Riley L, Edgar L. Why Older Adults Show Preference for Rational Over Emotional Advertising Appeals: A U.K. Brand Study Challenges the Applicability of Socioemotional Selectivity Theory to Advertising. Journal of Advertising Research. 2016;56(4),441-455. https://doi.org/10.2501/jar-2016-048

16. Kamran Q, Siddiqui DA. The Impact of Emotional Advertising on Consumer Buying Behavior for Home Appliance Products in Pakistan. Business and Management Horizons. 2019;7(1),23. https://doi.org/10.5296/bmh.v7i1.14410

17. Malik MS, Tanveer R. Effect of Rational Advertisement Appeal on Online Branding in Pakistan. International Journal of Industrial Marketing. 2018;3(1). https://doi.org/10.5296/ijim.v3i113635

18. Borborjafari M, Khorshid S, Rastegar A. Evaluating the Relationship of Rational Advertising Appeals, Cognitive Information Processing Styles of Consumers and Advertising Effectiveness. International Business Management. 2016;10(15). https://doi.org/10.36478/ibm.2016.2928.2934

19. Cambridge University Press. Cambridge Dictionary | English Dictionary, Translations \& Thesaurus. 2019. Retrieved from: http://dictionary.cambridge.org

20. Pouryousefi S, Frooman J. The Consumer Scam: An Agency-Theoretic Approach. Journal of Business Ethics. 2017;154(1),1-12. https://doi.org/10.1007/s10551-017-3466-x

21. UK Finance. Fraud the Facts 2019. The Definitive Overview of Payment Industry Fraud (4). 2019. Retrieved

from: https://www.ukfinance.org.uk/policy-andguidance/reports-publications/fraud-facts-2019

22. Aiman A. RM83mil lost to a "love scammers" so far this year. Free Malaysia Today. 2018. Retrieved from:

http://www.freemalaysiatoday.com/category/nation/ 2018/09/13/rm83mil-lost-to-love-scammers-so-farthis-year

23. Financial Intelligence Centre (FIC), Republic of Namibia. Advance Fee Fraud Schemes. 2019. Retrieved

from: https://www.fic.na/uploads/Public_Awareness/Fore warning_Reports/Advance\%20Fee\%20Fraud\%20S chemes.pdf
24. Borja ME, Brown ER. Covering New Fraud Risks with Traditional Policies. 2017. Retrieved February 16, 2020, from https://www.wiley.law/articleCovering-New-Fraud-Risks-With-TraditionalPolicies

25. Modic D, Anderson R, Palomäki J. We will make you like our research: The development of a susceptibility-to-persuasion scale. PLOS ONE. 2018;13(3),e0194119. https://doi.org/10.1371/journal.pone.0194119

26. Fogg BJ. Persuasive Technology: Using Computers to Change What We Think and Do (1st ed.). 2003. https://doi.org/10.1016/B978-1-55860-6432.X5000-8

27. Cialdini RB, Goldstein NJ. Social Influence: Compliance and Conformity. Annual Review of Psychology. 2004;55(1), 591-621. https://doi.org/10.1146/annurev.psych.55.090902.1 42015

28. Oinas-Kukkonen H, Harjumaa M. Persuasive Systems Design: Key Issues, Process Model, and System Features. Communications of the Association for Information Systems. 2009;24. https://doi.org/10.17705/1cais.02428

29. Muhammad Abdullahi A, Oyibo K, Orji R. The Influence of Cognitive Ability on the Susceptibility to Persuasive Strategies. Proceedings of the Personalization in Persuasive Technology Workshop. 2018. Retrieved from: http://ceurws.org/Vol-2089/3_Abdullahi.pdf

30. Anderson KB. Mass-Market Consumer Fraud: Who Is Most Susceptible to Becoming a Victim? (332). 2016. Retrieved from: http://www.ftc.gov/system/files/documents/reports/ mass-market-consumer-fraud-who-mostsusceptible-becomingvictim/working_paper_332.pdf

31. Modic D, Lea SEG. Scam Compliance and the Psychology of Persuasion. SSRN Electronic Journal. 2013. https://doi.org/10.2139/ssrn.2364464

32. Cialdini RB. Influence: science and practice (4th Ed.). Boston, MA; London: Allyn and Bacon. 2001.

33. Batra R, Homer PM, Kahle LR. Values, Susceptibility to Normative Influence, and Attribute Importance Weights: A Nomological Analysis. Journal of Consumer Psychology. 2001;11(2), 115128. https://doi.org/10.1207/S15327663JCP1102_04

34. Cacioppo JT, Petty RE, Feng Kao C. The Efficient Assessment of Need for Cognition. Journal of Personality Assessment. 1984;48(3), 306-307. https://doi.org/10.1207/s15327752jpa4803_13

35. Cialdini RB, Trost MR, Newsom JT. Preference for consistency: The development of a valid measure and the discovery of surprising behavioral implications. Journal of Personality and Social Psychology. 1995;69(2), 318-328. https://doi.org/10.1037/0022-3514.69.2.318

36 Andrews JC. The Dimensionality of Beliefs toward Advertising in General Journal of Advertising. $1989 ; 18(1)$, 26-35. https://doi.org/10.1080/00913367.1989.10673140 
37. Zimmermann G. Risk perception, emotion regulation, and impulsivity as predictors of risk behaviours among adolescents in Switzerland. Journal of Youth Studies. 2010;13(1), 83-99. https://doi.org/10.1080/13676260903173488

38. Fischer P, Kubitzki J, Guter S, Frey D. Virtual driving and risk taking: Do racing games increase risk-taking cognitions, affect, and behaviors? Journal of Experimental Psychology: Applied. 2007;13(1), 22-31. https://doi.org/10.1037/1076898X.13.1.22

39. Weber EU, Blais AR, Betz NE. A domain-specific risk-attitude scale: measuring risk perceptions and risk behaviors. Journal of Behavioral Decision Making. 2002,15(4),

263-290. https://doi.org/10.1002/bdm.414

40. Thaler RH, Shefrin HM. An Economic Theory of Self-Control. Journal of Political Economy. $1981 ; 89(2)$

392-406. https://doi.org/10.1086/260971

41. Tangney JP. Moral affect: The good, the bad and the ugly. Journal of Personality and Social Psychology, 1991;61(4), 598-60. https://doi.org/10.1037//0022-3514.61.4.598

42. Arnett J. Sensation seeking: A new conceptualization and a new scale. Personality and Individual Differences, 1994;16(2), 289-296. https://doi.org/10.1016/0191-8869(94)90165-1

43. Tian KT, Bearden WO, Hunter GL. Consumers' Need for Uniqueness: Scale Development and Validation. Journal of Consumer Research. 2001,28(1), 50-66. https://doi.org/10.1086/321947

44. Strathman A, Gleicher F, Boninger DS, Edwards CS. The consideration of future consequences: Weighing immediate and distant outcomes of behavior. Journal of Personality and Social Psychology. 1994;66(4), 742-752. https://doi.org/10.1037/0022-3514.66.4.742

45. Taylor SE, Brown JD. Illusion and well-being: A social psychological perspective on mental health. Psychological Bulletin. 1988;103(2), 193-210. https://doi.org/10.1037/0033-2909.103.2.193

46. Tsukayama E, Duckworth AL, Kim B. Resisting Everything Except Temptation: Evidence and an Explanation for Domain-specific Impulsivity. European Journal of Personality. 2011;26(3),318334. https://doi.org/10.1002/per.841

47. Whitty MT. Do You Love Me? Psychological Characteristics of Romance Scam Victims. Cyberpsychology, Behavior, and Social Networking. 2018;21(2), 105-109. https://doi.org/10.1089/cyber.2016.0729

48. Whitty MT. Predicting susceptibility to cyber-fraud victimhood. Journal of Financial Crime. 2019;26(1), 277-292. https://doi.org/10.1108/jfc10-2017-0095

49. Williams EJ, Beardmore A, Joinson AN. Individual differences in susceptibility to online influence: A theoretical review. Computers in Human Behavior. 2017;72, $412-421$. https://doi.org/10.1016/j.chb.2017.03.002
50. Van de Weijer SGA, Leukfeldt ER. Big Five Personality Traits of Cybercrime Victims. Cyberpsychology, Behavior, and Social Networking. 2017;20(7),

407-412. https://doi.org/10.1089/cyber.2017.0028

51. Mogaji E, Danbury A. Making the brand appealing: advertising strategies and consumers' attitude towards UK retail bank brands. Journal of Product \& Brand Management. 2017;26(6), 531-544. https://doi.org/10.1108/jpbm-07-2016-1285

52. Zhang Meadows C. The Effects of Fear Appeals and Message Format on Promoting Skin Cancer Prevention Behaviors among College Students. Societies. $2020 ; 10(1), \quad 21$. https://doi.org/10.3390/soc10010021

53. Sinha K, Sinha T, Sahdeo SN. Emotional and Fear Appeal in Advertising is an Effective Approach to Aware against Air Pollution in Society. International Journal of Applied Marketing and Management. 2017;2(2). Retrieved from: http://www.publishingindia.com/

ijamm/96/emotional-and-fear-appeal-in-advertisingis-an-effective-approach-to-aware-against-airpollution-in-society/638/4505/

54. Raza SH, Abu Bakar H, Mohamad B. Relationships between the Advertising Appeal and Behavioral Intention: The Mediating Role of the Attitude towards Advertising Appeal. SHS Web of Conferences. $2017 ; 33$. https://doi.org/10.1051/shsconf/20173300022

55. Maddux JE, Rogers RW. Protection motivation and self-efficacy: A revised theory of fear appeals and attitude change. Journal of Experimental Social Psychology. $1983 ; 19(5), 469-479$. https://doi.org/10.1016/0022-1031(83)90023-9

56. Witte K. Putting the fear back into fear appeals: The extended parallel process model. Communication Monographs; 1992;59,225-249.

57. Jansen J, Schaik PV. Persuading end users to act cautiously online: Initial findings of a fear appeals study on phishing. Proceedings of the Eleventh International Symposium on Human Aspects of Information Security \& Assurance (HAISA 2017). 2017.

58. Ngondo PS, Klyueva A Fear appeals in road safety advertising: an analysis of a controversial social marketing campaign in Russia. Russian Journal of Communication. 2019;11(2),167-183. https://doi.org/10.1080/19409419.2018.1555772

59. Qahtani EA, Shehab M, Aljohani A. The Effectiveness of Fear Appeals in Increasing Smartphone Locking Behavior among Saudi Arabians. USENIX Security Symposium 2018. 2018.

60. Wall JD, Buche MW. To fear or not to fear? A critical review and analysis of fear appeals in the information security context. Communications of the Association for Information Systems. 2017;41,277-300. https://doi.org/10.17705/1cais.04113

61. Shin S, Ki EJ, Griffin WG. The effectiveness of fear appeals in 'green' advertising: An analysis of 
creative, consumer, and source variables. Journal of Marketing Communications. 2017;23(5),473-492. https://doi.org/10.1080/13527266.2017.1290671

62. Meinard Y, Tsoukiàs A. On the rationality of decision aiding processes. European Journal of Operational Research. 2019;273(3),1074-1084. https://doi.org/10.1016/j.ejor.2018.09.009

63. Shukor MS, Sulaiman, Zuraidah, Thoo AC, Zakuan $\mathrm{N}$. The effect of emotional versus rational appeal in advertising on Malaysian consumers purchase intention of hybrid car. ARPN Journal of
Engineering and Applied Sciences. 2016;11(24). Retrieved from: http://www.arpnjournals.org/ jeas/research_papers/rp_2016/jeas_1216_5504.pdf

64. Kabir SMS. Basic Guidelines for Research: An Introductory Approach for All Disciplines (1st ed.). Chittagong, Bangladesh: Book Zone Publication. 2016.

65. Brown GTL, Irving SE, Keegan PJ An Introduction to Educational Assessment Measurement and Evaluation (3rd Ed.). Zaltbommel, Netherlands: Van Haren Publishing. 2014.

$$
\begin{aligned}
& \text { تأثير الخوف وتقتيات الفش في الاستئناف العقلاني على الحساسية الفردية } \\
& \text { نور هارياني زكريا }
\end{aligned}
$$

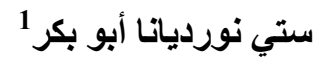

الخلاصة:

تظل عمليات الاحتيال من بين أهم حوادث الجر ائم الإلكترونية التي تحدث في جميع أنحاء العالم. ويعتبر الأفراد الذين لديهم قابلية

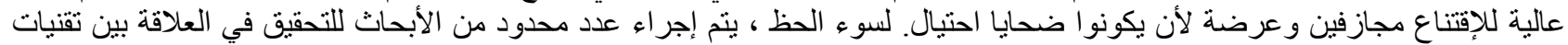

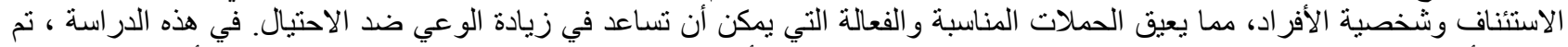

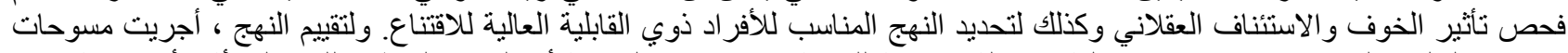

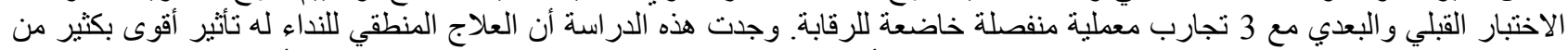
جاذبية الخوف. وتعتبر هذه النتيجة نقطة انطلاق في القاري اقتراح أن الاستئناف العقلاني هو وسيلة واعدة في إقناع الأفراد ذوي القابلية العالية لעقتناع. الكلمات المفتاحية: الخوف من الاستئناف، الاحتبال عبر الإنترنت، الاستئناف العقلاني، الاحتيال، القابلية للإقناع. 